\title{
DA INCONSTITUCIONALIDADE DA MEDIDA PROVISÓRIA 664/2014, QUE INSTITUIU O PRAZO MÍNIMO DE DOIS ANOS DE CASAMENTO PARA RECEBIMENTO DO BENEFÍCIO DA PENSÃO POR MORTE
}

Tamara de Souza Valério Mourão

ISSUE DOI: $10.21207 / 1983.4225 .291$

\section{RESUMO}

O presente trabalho tem por objetivo discorrer acerca da recente medida provisória n. 664/2014, convertida na Lei n. 13.135/2015, no tocante à modificação quanto à exigência de tempo mínimo de casamento/união estável para recebimento da pensão por morte. Para tanto, serão apresentados o histórico da alteração legislativa, a exposição de motivos da Medida Provisória, a análise da constitucionalidade formal e material de acordo com os princípios constitucionais da isonomia, da vedação ao retrocesso social, da razoabilidade e da proporcionalidade. A pesquisa se deu de modo bibliográfico e descritivo nas áreas do Direito Constitucional e Direito Previdenciário, utilizando-se o modo dedutivo e leituras crítico-reflexivas de fontes bibliográficas diversas (legislação pátria, doutrina e jurisprudência). 
Palavras-chave: Medida Provisória 664. Benefício Previdenciário. Pensão por morte. Casamento. União Estável. Inconstitucionalidade. Isonomia. Retrocesso social. Razoabilidade e Proporcionalidade. Lei $\mathrm{n}$. $13.135 / 2015$.

\section{INTRODUÇÃO}

De início, cabe trazer à discussão a origem do instituto. A pensão por morte é um dos benefícios previdenciários mais antigos previstos em nossa legislação. Sua origem remonta à criação do Decreto n. 4.682, de 24 de janeiro de 1923, que trazia, em seu artigo $9^{\circ}$, o seguinte texto:

Art. $9^{\circ}$ Os empregados ferro-viarios, a que se refere o art. $2^{\circ}$ desta lei, que tenham contribuido para os fundos da caixa com os descontos referidos no art. $3^{\circ}$, letra a, terão direito:

$1^{\circ}$, a soccorros medicos em casos de doença em sua pessôa ou pessôa de sua família, que habite sob o mesmo tecto e sob a mesma economia;

$2^{\circ}$, a medicamentos obtidos por preço especial determinado pelo Conselho de Administração;

$3^{\circ}$, aposentadoria:

$4^{\circ}$, a pensão para seus herdeiros em caso de morte. (texto original do decreto)

Este Decreto tratava, em verdade, de uma carreira específica, qual seja a dos empregados das empresas de estradas de ferro do País.

A partir daí, houve a previsão do instituto da pensão por morte em várias outras legislações esparsas e específicas de determinadas profissões, verificando-se apenas modificações no tocante à forma de custeio, pessoas beneficiadas e valor do benefício previdenciário a ser recebido.

Com o advento da vigente Constituição Federal de 1988, passou-se a assegurar no texto legal o recebimento da pensão por morte para os segurados pelo Regime Geral de Previdência Social, que previa, em seu artigo 201: 
Art. 201. Os planos de previdência social, mediante contribuição, atenderão, nos termos da lei, a:

I - cobertura dos eventos de doença, invalidez, morte, incluídos os resultantes de acidentes do trabalho, velhice e reclusão;

II - ajuda à manutenção dos dependentes dos segurados de baixa renda;

III - proteção à maternidade, especialmente à gestante;

IV - proteção ao trabalhador em situação de desemprego involuntário;

$V$ - pensão por morte de segurado, homem ou mulher, ao cônjuge ou companheiro e dependentes, obedecido o disposto no $\S 5^{\circ}$ e no art. 202 (texto original da Constituição).

Em contrapartida, foi criada, em 24 de julho de 1991, a Lei n. 8.213, que dispõe sobre os Planos de Benefícios da Previdência Social, na qual está regulamentado pormenorizadamente o benefício da pensão por morte, entre os artigos 74 a 79.

Pode-se verificar que, desde a sua criação, foram realizadas diversas modificações em seu texto, conforme se depreende do contido na Lei n. 9.032, de 28 de abril de 1995, na Lei n. 9.528, de 10 de dezembro de 1997, na Lei n. 12.470, de 31 de agosto de 2011, e, por fim, na recente modificação efetuada pela Lei n. 13.135, de 17 de junho de 2015 (Conversão da Medida Provisória n. 664/2014), objeto de estudo deste artigo.

\section{RAZÕES PARA ALTERAÇÃO LEGISLATIVA - EXPOSIÇÃO DE MOTIVOS DA MEDIDA PROVISÓRIA N. $664 / 2014$}

Tratando-se de nova proposta legislativa, necessária se faz a apresentação da exposição dos motivos que ensejaram a sua proposição. No caso em comento, passa-se a uma breve análise da EMI $\mathrm{n}$. 00023/2014 MPS MF MP, publicada em 30 de dezembro de 2014, apenas no tocante ao ponto a ser discutido neste artigo, qual seja a obrigatoriedade da necessidade de tempo mínimo de 2 (dois) anos de casamento ou união estável para recebimento do benefício da pensão por morte. 
Desta forma, está inicialmente prevista na citada exposição de motivos, em seu item de n. 3:

Como é do conhecimento de Vossa Excelência, a pensão por morte no âmbito do RGPS é um benefício concedido aos dependentes do segurado falecido, visando a preservar a dignidade daqueles que dele dependiam. Ocorre, entretanto, que as regras de acesso a tal benefício têm permitido distorções que necessitam de ajuste, tendo em vista estarem desalinhadas com os padrões internacionais $e$ com as boas práticas previdenciárias, possibilitando a concessão a pessoas que pouco contribuíram para o regime ou, o que é pior, até mesmo com apenas uma contribuição. Entre os principais desalinhamentos, podem ser citados: a) ausência de carência para pensão por morte previdenciária, apenas a qualidade de segurado; $b$ ) ausência de tempo mínimo de casamento ou união estável; c) beneficio vitalício para cônjuges, companheiros ou companheiras, independentemente da idade. A maioria dos países exige carência, tempo mínimo de casamento e tem tratamento diferenciado dependendo da idade do cônjuge (grifo do autor).

Nesse ponto da presente exposição de motivos, pode-se notar certa incoerência em sua justificativa. Veja-se: é dito inicialmente que o benefício da pensão por morte visa a preservar a dignidade dos que dependiam do instituidor do benefício. No entanto, ao afirmar que o benefício precisa sofrer reajustes tendo em vista estarem desalinhados com os padrões internacionais e com as boas práticas previdenciárias, introduz, na verdade, diversas limitações ao direito à dignidade dos dependentes do segurado, que primeiramente tentou-se resguardar.

Em verdade, não se pode levar em conta os padrões internacionais genericamente considerados, tendo em vista que, em nosso País, a forma de custeio e o próprio sistema previdenciário mostram-se com funcionamento diferente do que ocorre em outros Estados.

Ademais, foi feita uma menção abstrata à realização de "boas práticas previdenciárias", sem no entanto esclarecer do que se tratavam 
verdadeiramente. Assim, a justificativa apresentada na presente Exposição de Motivos mostrou-se por demais genérica, adotando parâmetros que dificilmente poderiam ser levados em conta de forma abstrata, ante a peculiaridade de cada caso.

Neste item, há menção a ser uma das causas principais do desalinhamento a ausência de tempo mínimo de casamento ou união estável. Neste ponto, tratando-se tal discussão do cerne do presente artigo, deixase para analisá-lo nos próximos tópicos da presente pesquisa.

Por fim, a alegação de que na "maioria dos países" existem requisitos que se propõem sejam instituídos em nosso País também se mostra inócua ante o já comentado caráter específico e único do Sistema Previdenciário brasileiro e, principalmente, as peculiaridades de cada benefício que devem ser observadas quando de sua concessão.

Outro ponto da Exposição de Motivos que merece ser comentado trata-se do item n. 7, que assim dispõe:

De igual maneira, é possível a formalização de relações afetivas, seja pelo casamento ou pela união estável, de pessoas mais idosas ou mesmo acometidas de doenças terminais, com o objetivo exclusivo de que o benefício previdenciário recebido pelo segurado em vida seja transferido a outra pessoa. Ocorre que a pensão por morte não tem a natureza de verba transmissível por herança e tais uniões desvirtuam a natureza da previdência social e a cobertura dos riscos determinados pela Constituição Federal, uma vez que a sua única finalidade é de garantir a perpetuação do benefício recebido em vida para outra pessoa, ainda que os laços afetivos não existissem em vida com intensidade de, se não fosse a questão previdenciária, justificar a formação de tal relação. Para corrigir tais distorções se propõe que formalização de casamento ou união estável só gerem o direito à pensão caso tais eventos tenham ocorrido 2 anos antes da morte do segurado, ressalvados o caso de invalidez do cônjuge, companheiro ou companheira após o início do casamento ou união estável, e a morte do segurado decorrente de acidente. 
Esse trecho da Exposição de Motivos traduz essencialmente que podem ocorrer situações em que as pessoas irão iniciar um relacionamento apenas considerando eventual recebimento de pensão por morte que possa vir a ocorrer após o falecimento do cônjuge ou companheiro.

Não se mostra positivo, e tampouco digno, levar-se em conta que o fato de as pessoas contraírem matrimônio com cônjuge que está próximo da morte se dá apenas com pensamento na possibilidade futura do recebimento da pensão por morte.

É fato que as pessoas se casam com o desejo de construir uma família, sendo esta a razão de se formarem, em sua maioria, os relacionamentos. Tal situação também é amplamente protegida pela Constituição Federal, que traz em seu texto constitucional que: "A família, base da sociedade, tem especial proteção do Estado". ${ }^{190}$

Assim, ainda que sejam realizados casamentos e simuladas uniões estáveis com o único objetivo de recebimento do benefício da pensão por morte, não pode tal situação ser tomada como regra, devendo o Estado se utilizar dos meios que possui para verificar e impedir tais acontecimentos.

A par disso, nota-se que a visão de preservação de dignidade que fôra inicialmente indicada no início da tratada Exposição de Motivos, mostrou-se inexistente ante os parâmetros que se quer adotar com a Medida Provisória apresentada.

\section{BREVE ANÁLISE DA CONSTITUCIONALIDADE FORMAL E MATERIAL DA MEDIDA PROVISÓRIA N. $664 / 2014$}

De acordo com previsão na Constituição da República, poderá ser redigida Medida Provisória pelo Presidente da República em caso de relevância e urgência, com força de lei, devendo submetê-las de imediato ao Congresso Nacional (art. 62, CF/1988).

Ainda em seu $\S 1^{\circ}$ prevê o artigo 62 que:

${ }^{190}$ BRASIL, 1988. Constituição da República Federativa do Brasil. Art. 226. 
$\S 1^{\circ}$ É vedada a edição de medidas provisórias sobre matéria: (Incluído pela Emenda Constitucional n ${ }^{\circ} 32$, de 2001)

I - relativa a: (Incluído pela Emenda Constitucional $\mathrm{n}^{\circ} 32$, de 2001)

a) nacionalidade, cidadania, direitos políticos, partidos políticos e direito eleitoral; (Incluído pela Emenda Constitucional $n^{\circ} 32$, de 2001);

b) direito penal, processual penal e processual civil; (Incluído pela Emenda Constitucional $\mathrm{n}^{\circ} 32$, de 2001);

c) organização do Poder Judiciário e do Ministério Público, a carreira e a garantia de seus membros; (Incluído pela Emenda Constitucional $\mathrm{n}^{\circ} 32$, de 2001);

d) planos plurianuais, diretrizes orçamentárias, orçamento e créditos adicionais e suplementares, ressalvado o previsto no art. 167, § $3^{\circ}$; (Incluído pela Emenda Constitucional $n^{\circ} 32$, de 2001);

II - que vise à detenção ou sequestro de bens, de poupança popular ou qualquer outro ativo financeiro; (Incluído pela Emenda Constitucional $\mathrm{n}^{\circ}$ 32, de 2001;)

III - reservada a lei complementar; (Incluído pela Emenda Constitucional $n^{\circ} 32$, de 2001);

IV - já disciplinada em projeto de lei aprovado pelo Congresso Nacional e pendente de sanção ou veto do Presidente da República. (Incluído pela Emenda Constitucional $\mathrm{n}^{\circ} 32$, de 2001).

Esses dois excertos previstos na Constituição demonstram a existência de determinados parâmetros que a Medida Provisória deve obedecer para que esteja de acordo com a previsão constitucional, ou seja, para que se apresente formal e materialmente constitucional.

A constitucionalidade formal está prevista no caput do artigo 62 quando requer que a Medida Provisória seja criada pelo Presidente da República, em caso de relevância e urgência.

No tocante à constitucionalidade material, esta encontra-se exposta no $\S 1^{\circ}$ do artigo 62 , que dispõe sobre as matérias de que a Medida Provisória não poderá tratar. 


\subsection{Da inconstitucionalidade formal}

No tocante ao aspecto da constitucionalidade formal da Medida Provisória n. 664/2014, devem ser observados os parâmetros contidos no caput do artigo 62 da Constituição Federal, in verbis:

"Art. 62. Em caso de relevância e urgência, o Presidente da República poderá adotar medidas provisórias, com força de lei, devendo submetê-las de imediato ao Congresso Nacional". (Redação dada pela Emenda Constitucional $n^{\circ} 32$, de 2001 - (grifei).

Ao analisar a Exposição de Motivos e o conteúdo textual da presente Medida Provisória, não se verificam presentes os requisitos da relevância e urgência. Tal Medida foi criada sem obedecer a esses parâmetros, daí porque falar-se em inconstitucionalidade formal da Medida Provisória em comento.

De acordo com entendimento doutrinário da lavra do Ministro do Supremo Tribunal Federal, Gilmar Mendes: "Para que se legitime a edição da medida provisória, há de estar configurada uma situação em que a demora na produção da norma possa acarretar dano de difícil ou impossível reparação para o interesse público". ${ }^{191}$

Nas palavras do também Ministro do Supremo Tribunal Federal, Celso de Mello, na ADI-MC 293, DJ de 16.4.1993, citado por Mendes:

O que justifica a edição de medidas provisórias, com força de lei, em nosso direito constitucional, é a existência de um estado de necessidade que impõe ao Poder Público a adoção imediata de providências, de caráter legislativo, inalcançáveis segundo as regras ordinárias de legiferação, em face do próprio periculum in mora que fatalmente decorreria do atraso na concretização da prestação legislativa. ${ }^{192}$

191 MENDES, Gilmar Ferreira e BRANCO, Paulo Gustavo Gonet. Curso de Direito Constitucional. 7a. edição. São Paulo: Saraiva, 2012.

192 MENDES, Gilmar Ferreira e BRANCO, Paulo Gustavo Gonet. Curso de Direito Constitucional. 7a. edição. São Paulo: Saraiva, 2012. 
Dessa forma, havendo previsão constitucional da forma como deve ser criada a Medida Provisória, é de notar-se que, no caso da Medida n. 664/2014, não houve obediência a esses requisitos, padecendo esta, então, do vício da inconstitucionalidade formal.

\subsection{Da inconstitucionalidade material}

No tocante à inconstitucionalidade material, essa diz respeito ao conteúdo essencialmente tratado na legislação. Diz-se que determinada norma é inconstitucional quando está em desacordo com os ditames contidos na Constituição Federal do País.

Para Luís Roberto Barroso,

... a inconstitucionalidade material expressa uma incompatibilidade de conteúdo, substantiva entre a lei ou o ato normativo e a Constituição. Pode traduzir-se no confronto com uma regra constitucional - e.g., a fixação da remuneração de uma categoria de servidores públicos acima do limite constitucional (art. 37, XI) - ou com um princípio constitucional, como no caso de lei que restrinja ilegitimamente a participação de candidatos em concurso público, em razão do sexo ou idade (arts. $5^{\circ}$, caput, e $3^{\circ}$, IV), em desarmonia com o mandamento da isonomia. O controle material de constitucionalidade pode ter como parâmetro todas as categorias de normas constitucionais: de organização, definidoras de direitos e programáticas". ${ }^{193}$

Assim, elenca-se a seguir alguns princípios contidos em nossa Constituição Federal e que se mostram claramente afrontados com a nova previsão contida na Medida Provisória n. 664/2014, que exige o tempo

193 BARROSO, Luís Roberto. Curso de Direito Constitucional Contemporâneo: os conceitos fundamentais e a construção do novo modelo. 4ª Edição. São Paulo: Saraiva, 2013. 
mínimo de dois anos de casamento ou união estável para se ter direito ao recebimento da pensão por morte.

\subsubsection{Princípio da Isonomia}

O Princípio da Isonomia ou Princípio da Igualdade é um dos pilares da Constituição de 1988. Traduz-se essencialmente no dizer de que se deve "tratar igualmente os iguais na medida de suas desigualdades". Desta forma, admite-se a distinção de tratamento entre pessoas que essencialmente não se apresentem na mesma situação, buscando realizar-se a justeza na conduta.

Assim, cediço que o texto constitucional ampara a instituição do casamento e da união estável nos seguintes termos:

Art. 226. A família, base da sociedade, tem especial proteção do Estado.

$\S 1^{\circ} \mathrm{O}$ casamento é civil e gratuita a celebração.

$\S 2^{\circ} \mathrm{O}$ casamento religioso tem efeito civil, nos termos da lei.

$\S 3^{\circ}$ Para efeito da proteção do Estado, é reconhecida a união estável entre o homem e a mulher como entidade familiar, devendo a lei facilitar sua conversão em casamento.

$\S 4^{\circ}$ Entende-se, também, como entidade familiar a comunidade formada por qualquer dos pais e seus descendentes.

$\S 5^{\circ}$ Os direitos e deveres referentes à sociedade conjugal são exercidos igualmente pelo homem e pela mulher.

$\S 6^{\circ} \mathrm{O}$ casamento civil pode ser dissolvido pelo divórcio. (Redação dada Pela Emenda Constitucional $\mathrm{n}^{\mathrm{o}} 66$, de 2010).

$\S 7^{\circ}$ Fundado nos princípios da dignidade da pessoa humana e da paternidade responsável, o planejamento familiar é livre decisão do casal, competindo ao Estado propiciar recursos educacionais e científicos para o exercício desse direito, vedada qualquer forma coercitiva por parte de instituições oficiais ou privadas. 
$\S 8^{\circ} \mathrm{O}$ Estado assegurará a assistência à família na pessoa de cada um dos que a integram, criando mecanismos para coibir a violência no âmbito de suas relações.

O texto da Medida Provisória aqui discutida é o seguinte:

Art. 74.

$\S 2^{\circ} \mathrm{O}$ cônjuge, companheiro ou companheira não terá direito ao benefício da pensão por morte se o casamento ou o início da união estável tiver ocorrido há menos de dois anos da data do óbito do instituidor do benefício, salvo nos casos em que:

I - o óbito do segurado seja decorrente de acidente posterior ao casamento ou ao início da união estável; ou

II - o cônjuge, o companheiro ou a companheira for considerado incapaz e insuscetível de reabilitação para o exercício de atividade remunerada que lhe garanta subsistência, mediante exame médicopericial a cargo do INSS, por doença ou acidente ocorrido após o casamento ou início da união estável e anterior ao óbito.

Ressalva-se que, quando da Conversão da Medida Provisória na Lei n. 13.135/2015, esse trecho foi modificado novamente, passando a constar o seguinte:

Art. 77.

$\S 20 \quad \mathrm{O}$ direito à percepção de cada cota individual cessará:

$\mathrm{V}$ - para cônjuge ou companheiro:

b) em 4 (quatro) meses, se o óbito ocorrer sem que o segurado tenha vertido 18 (dezoito) contribuições mensais ou se o casamento ou a união estável tiverem sido iniciados em menos de 2 (dois) anos antes do óbito do segurado;

A modificação apresentada pela Medida Provisória afronta claramente o princípio constitucional da isonomia, uma vez que impõe uma 
restrição de direito a pessoas que se encontram na mesma situação jurídica, quais sejam os cônjuges ou companheiros.

Não há no texto constitucional que trata da proteção ao casamento qualquer restrição no tocante a período em que as pessoas devem permanecer casadas ou em união estável para ser reconhecida a eficácia no casamento. As pessoas são reconhecidas como casadas a partir do momento previsto na legislação constitucional, estando em desacordo com a Lei Maior qualquer tratamento diferenciado que seja dado a elas.

Dessa forma, quando a Medida Provisória prevê esse período mínimo de casamento ou união estável, está tratando desigualmente pessoas que se encontram em uma mesma situação, sem qualquer justificativa para tal. Esse fato é inadmissível em nosso ordenamento jurídico, uma vez que a proteção do princípio da igualdade é prevista na Constituição Federal, não podendo ser desrespeitada pelas legislações esparsas.

\subsubsection{Princípio da vedação ao retrocesso social}

Na lição de Luís Roberto Barroso, traduz-se o Princípio da Vedação ao Retrocesso Social em:

Por este princípio, que não é expresso, mas decorre do sistema jurídico-constitucional, entende-se que se uma lei, ao regulamentar um mandamento constitucional, instituir determinado direito, ele se incorpora ao patrimônio jurídico da cidadania e não pode ser absolutamente suprimido. ${ }^{194}$

A partir desta definição ora apresentada, mostra-se de forma inconteste a violação a tal princípio, apresentada pela modificação da Medida Provisória 664/2014. A previsão anterior, que se mostrava de acordo com os ensinamentos da Constituição Federal, não trazia qualquer restrição às pessoas casadas ou companheiras no tocante ao recebimento da pensão por morte.

194 BARROSO, Luís Roberto. Curso de Direito Constitucional Contemporâneo: os conceitos fundamentais e a construção do novo modelo. $4^{\mathrm{a}}$. Edição. São Paulo: Saraiva, 2013. 
Vê-se que, a partir da mudança apresentada pela Medida Provisória, houve verdadeiro retrocesso na questão da proteção constitucional a esse direito que até então era ampla e inviolavelmente assegurado.

Além disso, este Princípio já vem sendo analisado e reconhecido em nosso ordenamento jurídico, quando se refere a determinados julgamentos realizados pelo Supremo Tribunal Federal, conforme se expõe abaixo:

A PROIBIÇÃO DO RETROCESSO SOCIAL COMO OBSTÁCULO CONSTITUCIONAL À FRUSTRAÇÃO E AO INADIMPLEMENTO, PELO PODER PÚBLICO, DE DIREITOS PRESTACIONAIS. - O princípio da proibição do retrocesso impede, em tema de direitos fundamentais de caráter social, que sejam desconstituídas as conquistas já alcançadas pelo cidadão ou pela formação social em que ele vive. - A cláusula que veda o retrocesso em matéria de direitos a prestações positivas do Estado (como o direito à educação, o direito à saúde ou o direito à segurança pública, v.g.) traduz, no processo de efetivação desses direitos fundamentais individuais ou coletivos, obstáculo a que os níveis de concretização de tais prerrogativas, uma vez atingidos, venham a ser ulteriormente reduzidos ou suprimidos pelo Estado. Doutrina. Em conseqüência desse princípio, o Estado, após haver reconhecido os direitos prestacionais, assume o dever não só de torná-los efetivos, mas, também, se obriga, sob pena de transgressão ao texto constitucional, a preservá-los, abstendo-se de frustrar - mediante supressão total ou parcial - os direitos sociais já concretizados (ARE 639337 AgR / SP SÃO PAULO - AG.REG. NO RECURSO EXTRAORDINÁRIO COM AGRAVO - Relator(a): Min. CELSO DE MELLO - Julgamento: 23/08/2011 - Órgão Julgador: Segunda Turma).

Resta demonstrado então, que tal princípio, além de seu reconhecimento doutrinário, detém também reconhecimento da jurisprudência pátria, que já mostrou, em outros casos relativos à proteção aos direitos 
fundamentais e sociais, admitir o Princípio da Vedação ao Retrocesso Social, visando a resguardar demais situações desta espécie.

\subsubsection{Princípio da razoabilidade e proporcionalidade}

Ao final, para demonstrar uma outra forma em que a mudança apresentada pela Medida Provisória n. 664/2014 afronta os ensinamentos primordiais da Constituição Federal, fala-se aqui do Princípio da Razoabilidade e da Proporcionalidade.

De acordo com a balizada doutrina de Luís Roberto Barroso, estes princípios podem ser decompostos em outros três subprincípios, quais sejam: adequação, necessidade e proporcionalidade.

Ainda de acordo com Barroso, deve existir adequação entre o meio empregado e o fim perseguido, isto é, idoneidade da medida para produzir o resultado visado.

Deve ser observada também a necessidade da medida, sendo preciso verificar-se a inexistência de meio menos gravoso para a consecução dos fins visados.

E ao final, tratando-se da proporcionalidade em sentido estrito, esta diz respeito à ponderação entre o ônus imposto e o benefício trazido, para se constatar se a medida é legítima. ${ }^{195}$

Após esta breve explanação dos desdobramentos que encontramos ao tratar do Princípio da Proporcionalidade e Razoabilidade, passa-se à análise do caso concreto em estudo com a teoria aqui mencionada.

A mudança imposta pela MP 664/2014 certamente não obedeceu aos ditames previstos neste princípio constitucional. Não se mostra adequada a previsão de que apenas casais a partir de dois anos de convivência marital tenham direito ao recebimento de pensão por morte. Isso porque criou-se uma limitação temporal a partir da qual subentende-se que passa o relacionamento a ser válido.

Tratando-se do aspecto de necessidade da medida, também não há como se entender ser este o meio menos gravoso para a consecução dos fins visados. A mudança foi realizada supostamente sob alegação de

195 BARROSO, Luís Roberto. Curso de Direito Constitucional Contemporâneo: os conceitos fundamentais e a construção do novo modelo. $4^{\mathrm{a}}$. Edição. São Paulo: Saraiva, 2013. 
se evitar fraudes; no entanto, o Estado poderia se utilizar de outros meios para investigar e identificar os supostos relacionamentos que acredita estar nessa situação.

Não se mostra razoável simplesmente supor que todos os casais com menos de dois anos de relacionamento não detêm direito igual aos dos outros.

Sobre a proporcionalidade em sentido estrito, aqui resta demonstrada a maior falha imposta pela MP 664/2014. Impor um limite temporal para reconhecer-se o direito ao recebimento da pensão por morte fere verdadeiramente o sentido da palavra "proporcionalidade".

Verifica-se que o ônus a ser suportado pelos dependentes do segurado nessa situação é imensamente desproporcional ao benefício que se procura verter.

O fato de ser justificada como necessária tal situação, visando ao equilíbrio econômico-financeiro dos benefícios previdenciários, não convence a utilização de tamanha desproporção que será enfrentada pelos casais com tempo de relacionamento inferior a 2 (dois) anos.

Dessa forma, resta demonstrada, mais uma vez, a violação trazida também a este princípio constitucional, que deve ser observado por toda e qualquer legislação em vigor no nosso ordenamento jurídico.

\section{CONSIDERAÇÕES FINAIS}

A Medida Provisória n. 664/2014 foi publicada em 30 de dezembro de 2014 e convertida na Lei n. 13.135 de 17 de junho de 2015.

O texto inicial da Medida Provisória previa que o cônjuge/companheiro não teria direito à pensão por morte se o casamento/união estável tivesse ocorrido há menos de dois anos da data do óbito do instituidor do benefício, salvo nos casos de óbito do segurado por acidente ou cônjuge/companheiro incapaz e insuscetível de reabilitação.

Contudo, quando da conversão da Medida Provisória em lei, esta previsão foi modificada, mantendo-se a previsão do tempo mínimo de casamento, acrescentando-se que, em tais casos, o cônjuge/companheiro terá direito ao recebimento da pensão por morte apenas pelo período de 4 (quatro) meses. 
Após percorrer toda a discussão bibliográfica apresentada no presente estudo, chega-se à conclusão de que, efetivamente, a MP $664 / 2014$, convertida na Lei n. 13.135/2015, mostra-se inconstitucional em seus aspectos formal e material.

Sabe-se que já foram propostas perante o STF pelos menos 4 (quatro) Ações Diretas de Inconstitucionalidade em desfavor da aqui tratada Medida Provisória. Assim, ao enfrentar os debates sobre os temas por ora discutidos, certamente o Pretório Excelso adentrará nos aspectos que foram explanados, especialmente no tocante aos princípios constitucionais que estão sendo violados.

Dessa forma, espera-se uma resposta do Supremo Tribunal Federal que atenda aos ditames constitucionais já mencionados, para que se possa novamente afirmar que tais direitos e princípios estão e devem permanecer sendo protegidos pela nossa Constituição Federal.

\section{REFERÊNCIAS BIBLIOGRÁFICAS}

BARROSO, Luís Roberto. Curso de Direito Constitucional Contemporâneo: os conceitos fundamentais e a construção do novo modelo. 4 ${ }^{\mathrm{a}}$. Edição. São Paulo: Saraiva, 2013.

CAVALCANTI, Alessandra Damian. O retrocesso social promovido pela Medida Provisória 664/2014 que alterou a Lei 8.112/90, retirando direitos previdenciários dos servidores públicos. Disponível em < http://sindireceita.org.br/blog/o-retrocesso-socialpromovido-pela-medida-provisoria-6642014-que-alterou-a-lei-811290-retirando-direitos-previdenciarios-dos-servidores-publicos/ $>$. Acesso em 2 jun. 2015

LENZA, Pedro. Direito Constitucional Esquematizado. 14a . edição. São Paulo: Saraiva, 2010.

MACEDO, Alan da Costa. Análise da Exposição de Motivos - EMI n. 0023/2014 - que originou a Medida Provisória 664/2014 - em relação ao benefício de pensão por morte. Disponível em < http://imeprep.com.br/images/artigos/0093_artigo.pdf $>$. Acesso em 02 jun. 2015.

MENDES, Gilmar Ferreira e BRANCO, Paulo Gustavo Gonet. Curso de Direito Constitucional. 7a. edição. São Paulo: Saraiva, 2012. 
NOVELINO, Marcelo. Manual de Direito Constitucional. 8 ${ }^{a}$. Edição. São Paulo: Método, 2013.

SARLET, Ingo Wolfgang. A eficácia do direito fundamental à segurança jurídica: dignidade da pessoa humana, direitos fundamentais e proibição de retrocesso social no Direito Constitucional Brasileiro. Disponível em < http://www.mundojuridico.adv.br >. Acesso em 2 de jun. 2015. 
